Steven J. Bell and Michael J. Krasulski

\title{
What's Google up to now? Online resources for keeping up with Google and search engines
}

G oogle is a whirlwind of innovation. In the period between April and June 2006, Google introduced Google Calendar, Google Notebook, Google Trends, Google Checkout, Google Spreadsheet, and a new version of Google Desktop with Google Gadgets. All the while Google continues to tinker with its agship search product. With nearly 50 percent of the market, Google is the dominant force on the search engine landscape. Because of this, no matter how you personally feel about Google as a librarian, the one position that none of us can afford to take is choosing to ignore what Google is doing and plans to do. Put simply, librarians need to be Google experts.

Google is a form of competition for academic libraries. To effectively promote our own services and resources, librarians must differentiate them from Google s offerings, but to do so we must understand well the competitor s products and services. We must encourage the members of our user communities to take full advantage of their many information options. That includes search engines, library databases, and everything in between. Individual users should be able to match their information need to the best possible resource.

Academic librarians can promote success with user education that demonstrates when Google works best or when a library database is the right choice. Think of it as being able to show the competitive advantage of using library databases. Keeping up is a form of competitive intelligence. Knowing more about Google, especially future innovations and initiatives, simply enables us to be more competent in educating our user community. Fortunately, developing Google expertise is facilitated by an abundance of news sources about the company and its products.

\section{Go with blogs about Google}

The preferred strategy for keeping up with Google is following any of several useful blogs dedicated to Google. If you haven t started taking advantage of RSS (Real Simple Syndication) and news aggregator technology to enhance your keeping up regimen, this is the time to get started. It is far easier to follow several of the blogs described below using news aggregator technology than to bookmark these sites and try to remember to visit them regularly. The beauty of RSS and aggregators is the elimination of tracking resources. Instead, all of the content is pushed to the reader for review at his or her convenience. There are several excellent tutorials for getting started with RSS and aggregators. A starting point is staff.philau. edu/bell/rss.htm. After subscribing to a news aggregator, your journey to Google expertise can begin here. ${ }^{1}$

\section{All about Google}

The following blogs focus primarily on Google and nothing but Google.

Google Blog. The official blog of Google, Inc., Google Blog is the company s flagship blog about its services and op-

Steven J. Bell is director of the library, e-mail: bells@philau. edu, and Michael J. Krasulski is coordinator of public services, e-mail: krasulskim@philau.edu, at Philadelphia University's Paul J. Gutman Library

๑ 2006 Steven J. Bell and Michael J. Krasulski 
erations, and is clearly the best resource for keeping up with news about and activity at Google, Inc. Google employees post news, information, and insights about Google. Typical posts include Google Gossip, tips sent in by Google users, and new product announcements. Like the search engine itself, the blog is clutter free and easy to navigate. Google Blog is naturally the primary news source for a host of Google bloggers. However, being the voice of Google negates this resource of any critical evaluation of Google products or activities. Think of it as going to a company s own Web site to get information about the company; you can expect some bias. Google Blog is necessary in your Google regimen. Access: http://www.google.com/googleblog.

Inside Google Book Search. Online since May 2006, Inside Google Book Search is the newest blog by Google, Inc. and is dedicated wholly to the Google Print project. Librarians can learn rsthand about the Google Print project from employees who share helpful Google Print tips and announcements. Recent posts reported author news, book convention activity, and even ALA s Annual Conference in New Orleans. Readers may submit their own Google Print search success stories to this blog. Our analysis indicates that posts to Inside Google Book Search are rarely duplicated in other Google blogs. If you intend to be the Google expert at your library, Inside Google Book Search is a must read. RSS feed is available. Access: http://booksearch.blogspot.com/.

Inside Google Desktop. Another of Google s of cial blogs, this one is dedicated to Google Desktop. Online since November 2005 , typical posts include developer- and user-contributed tips, feature descriptions, and ideas on how to maximize Google Desktop. Given this blog s narrow focus, posts on Inside Google Desktop are hardly mentioned on any of the other blogs discussed in this article. Consider checking Inside Google Desktop for unique Google news. Otherwise add it to your RSS aggregator only if you are interested in Inside Google Desktop. Access: http://googledesktop.blogspot.com/.
Googling Google. Garett Rogers, programmer at iQmetrix (a retail management software company), maintains Googling Google. Rogers interest in Google began upon the behest of his employer who wanted him to get a better handle on Google. Typical posts include tips to maximize Google search, commentary on new Google features, and critical evaluation of Google s tools. Rogers excellent screenshots illustrate his points. It is refreshing to see a blogger critically evaluate Google s features. Owing to a cluttered page design, this blog is less effective than it could be. Though not necessarily the rst stop for Google news, consider adding Googling Google into your favorite RSS feed aggregator. Access: http://blogs.zdnet.com/Google/.

Topix Google News. Online since 2002, Topix is by design a one-stop source for news and information about speci c topics. The sources used by Topix are unique and rarely found on many of the other resources consulted for this article. Topix reporting leans toward business news about corporate Google, but its real value is its coverage of advances and news from Google Labs the research and development division of Google, Inc. Topix supports search alerts for those who want noti cation anytime new Google information is added to the News. Because it draws on thousands of sources for Google news, this site rivals Google s own for news and information, but provides it without any inherent bias. Access: http://www.topix. net/com/google.

\section{Subscribe to the Google News and Information reading list}

For an OPML reading list containing many of the resources in this article, visit Steven Bell's Keeping Up Web site at staff.philau. edu/bells/keepup/readinglists.htm.When you input the OPML file into your news aggregator, it will automatically subscribe to all the included RSS feeds.

New to RSS and OPML? The page includes instructions to get you started. 
UBC Google Scholar Blog. Dean Giustini, a reference librarian at the University of British Columbia (UBC), maintains the Google Scholar Blog. Online since April 2005, Giustinis blog is focused primarily on Google for health science librarians and medical professionals. He pulls his news postings from the usual variety of sources, including professional journals, blogs, newspapers, and resources mentioned elsewhere in this article. There are occasional posts about other search engines and subscription-based periodical databases. The blog is low on clutter and rather easy to navigate. UBC Google Scholar Blog is a must for health science librarians. RSS feed is also available. Access: http://careo.elearning.ubc.ca /weblogs/googlescholar.

\section{Google plus}

Google is the primary focus of these blogs, but they occasionally report on other search engines or search engine industry developments.

Google Operating System. A Romanian student, Ionut Alex Chitu, maintains Google Operating System (GOS), which has been online since October 2005. Chitu gathers

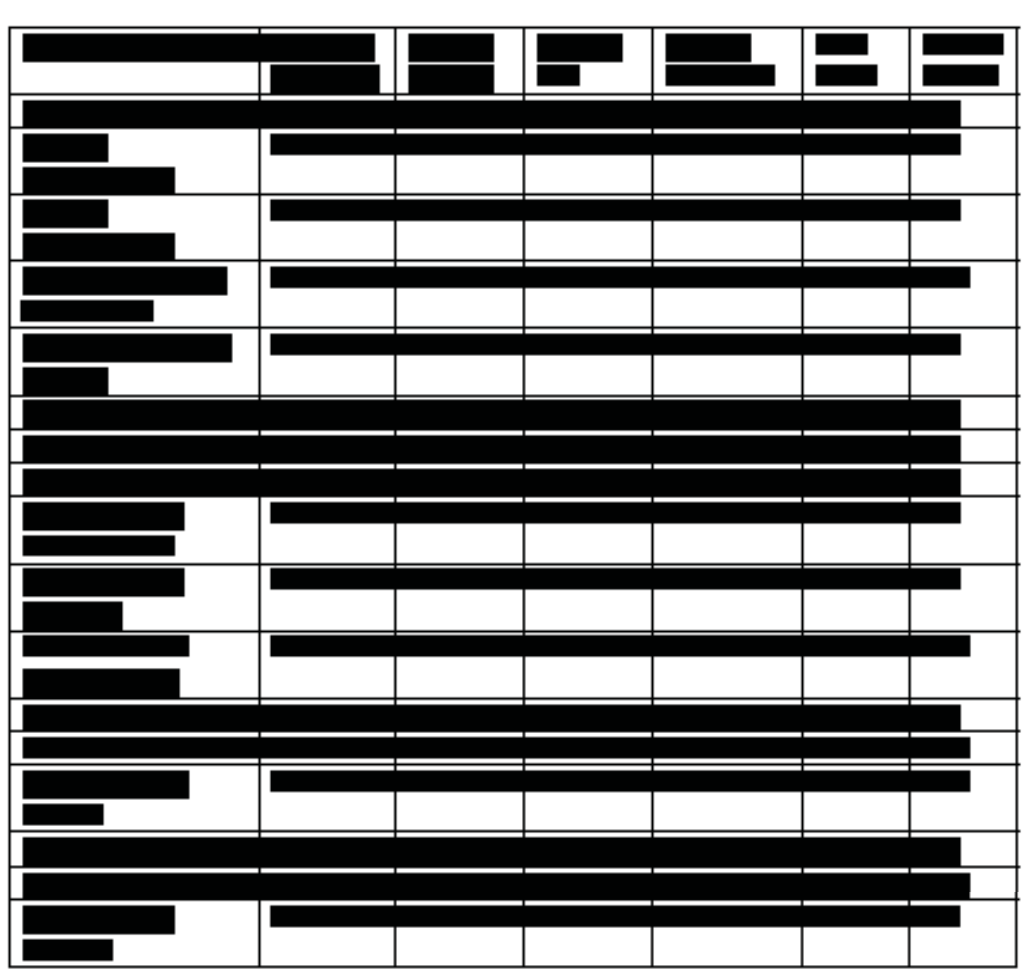

AAG=All About Google, GMM=Google and Much More, $G P=$ Google Plus his news stories from the periodical literature, mainly the New York Times and Wired, and several of the blogs mentioned elsewhere in this article. In addition to the usual Google news, GOS tends to look at the lighter side of Google. Chitu has a knack for discovering Google blunders. While GOS offers some mild Google humor along with its reporting of Google news and related software, it is not the rst place to check for breaking Google news. RSS available. Access: http://googlesystem.blogspot.com/.

Google Weblog. Aaron Swartz maintains Google Weblog. Tracking Google since 2002, Swartz presents readers commentaryfree Google news from a variety of sources, including InsideGoogle, GoogleBlog, and major North American newspapers. He offers a streamlined blog that is easy to read and navigate. Google Weblog is certainly worth considering. Access: http://google.blogspace. $\mathrm{com} /$.

InsideGoogle. Online since December 2004, InsideGoogle is a part of the Blog News Channel and is maintained by Nathan Weinberg. Google is the focus of the blog, but news about other engines creeps in on occasion. While InsideGoogle tends to draw

a fair number of stories from Searchenginewatch, it adds original content about Google s latest activities and presents it in a well-organized fashion. InsideGoogle makes for worthwhile reading, but even more interesting is the extensive list of blogs Weinberg assembles concerning Microsoft, Google, search engines, tech news, non-English blogs, and blogs by Microsoft and Google employees. This site effectively adds an international perspective to a Google keeping-up regimen. Access: http:// google.blognewschannel. com. 


\section{Google and much more}

Should you want to go beyond Google in your keeping-up regimen, consider search engine reporters, which go beyond Google. The resources below are more balanced in their coverage. These report news about the search engine industry. We recommend the following:

Google Blogoscoped. Access: http:// blog.outer-court.com.

Google Librarian Newsletter. Access: http://www.google.com/librariancenter/librarian_newsletter.html.

Pandia Search Engine News. Access. http://www.pandia.com/sew/index.php.

Phil Bradley's Weblog. Access: http:// philbradley.typepad.com/.

ResearchBuzz. Access: http://www. researchbuzz.org/wp/.

SearchengineBlog. Access: http:// www.searchengineblog.com/.

Search Engine Watch. Access: http:// searchenginewatch.com/sereport/.

Want additional Google news customized to your own speci c interests? Most search engines now create an alert or RSS feed for virtually any search topic. For example, a YAHOO! search on google academic libraries will generate both a news alert and an RSS feed. The news alert delivers an e-mail based alert while the RSS feed sends news to an aggregator, but both push any new articles generated by this search as new information is added to YAHOO!. Be sure to choose news rather than Web as the search content. Sources such as YAHOO! News, Google News, and Findory (www. ndory. com) provide access to tens of thousands of additional news outlets making it easy to pick up those Google news items that meet your needs.

\section{Conclusion}

Keeping up is all about time, or more often our lack of it. The number one reason librarians fail to keep up effectively is insuf cient time. Think of keeping up with Google as an investment of time. Like most investments there is risk. Keeping up will sometimes yield little news or information of value, but, without fail, those who keep up conscientiously will be rewarded with a gem of information that is the return on the investment. Granted, if something as signi cant as GooglePrint happens we all hear about it in short time. But the reality is that Google is now a news machine, constantly generating stories both signi cant and minor. Which are the ones we can afford to miss?

\section{Reference}

Fallows, Deborah. (2005) Search engine users. Washington, D.C.: Pew Internet and American Life Project, 2005. Retrieved on April 27, 2005 www.pewinternet.org/pdfs /PIP_Searchengine_users.pdf.

\section{Note}

1. All the sites reviewed were accessed during the month of July 2006. We appreciate the advice received for our colleague Gary Price $\pi$

\section{Focus on $50+$}

AARP's Ageline Database Social gerontology 8 aging-related research, policy, and practice

FREE searching at: www.aarp.org/ageline

Also available on CSA Dialog, EBSChost Ovid, \& SilverPlatter agelinesaarp.org

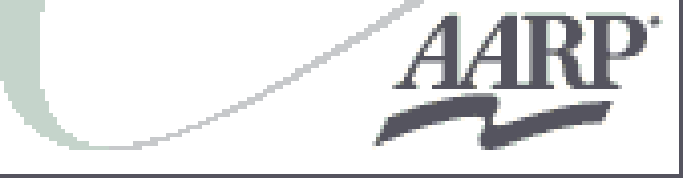

